\title{
Childhood Acute Lymphoblastic Leukemia
}

National Cancer Institute

\section{Source}

National Cancer Institute. Childhood Acute Lymphoblastic Leukemia. NCI Thesaurus.

Code C3168.

An acute lymphoblastic leukemia occurring during childhood. The majority of cases are Bacute lymphoblastic leukemias. Approximately $15 \%$ of the cases are T-acute lymphoblastic leukemias. 